This item was submitted to Loughborough's Institutional Repository (https://dspace.lboro.ac.uk/) by the author and is made available under the following Creative Commons Licence conditions.

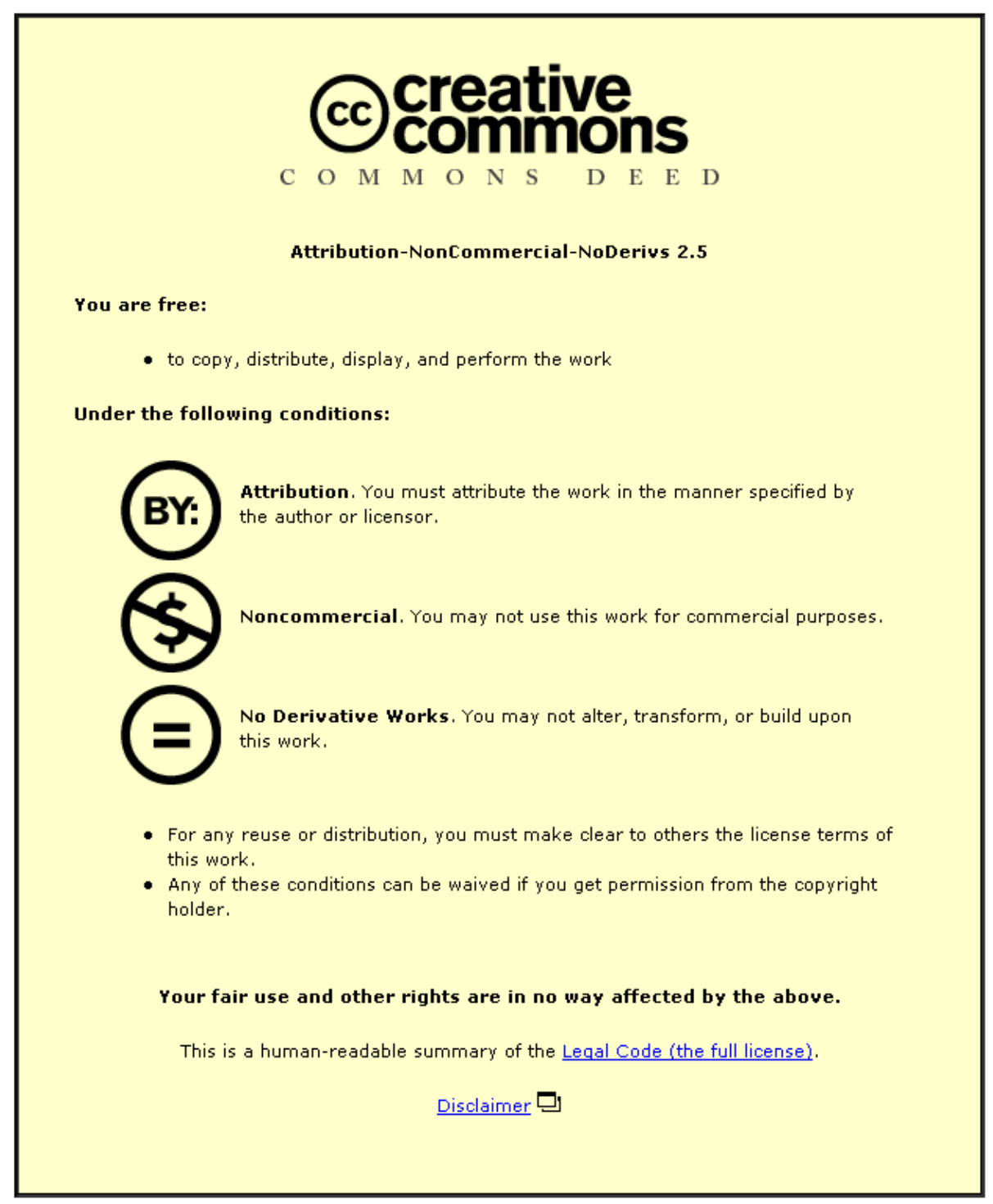

For the full text of this licence, please go to: http://creativecommons.org/licenses/by-nc-nd/2.5/ 


\title{
The Effects of Area-wide Road Speed and Curvature on Traffic Casualties in England
}

\author{
Chao Wang, Mohammed Quddus, Stephen Ison* \\ Transport Studies Group, Loughborough University, Loughborough, Leicestershire, \\ LE11 3TU, UK \\ * Corresponding author, s.g.ison@lboro.ac.uk
}

\begin{abstract}
Transport provides a range of benefits to society in terms of mobility, access and economic growth. There are however negative impacts of transport, not least in terms of environmental degradation, damage to property, traffic accidents and loss of life. This paper focuses on road traffic accidents, the reduction of which is an important aim of transport policy world wide. The primary objective of this paper is to develop a series of relationships using spatially disaggregated area-level cross-sectional data between different traffic casualties, road traffic speed and road curvature by controlling for other contributing factors associated with area characteristics. The spatial units of the analysis are the 8019 census wards in England. Wardlevel casualty data are disaggregated by severity of the casualty (such as fatalities, serious injuries, and slight injuries) and by the severity of the casualty related to various road users.

The results suggest that increased average speed within a ward is positively associated with total fatalities and serious injuries; and road curvature is found to be a protective factor.
\end{abstract}

Key words: Transport safety; Area-wide road speed; curvature; spatial analysis; GIS

\section{INTRODUCTION}

Transport brings huge benefits to society, but it also has costs. The costs include not only the direct cost of providing transport services such as infrastructure, personnel and equipment costs but also the various indirect costs in terms of loss of life and property damage as a result of traffic accidents, travel delay due to traffic congestion and air pollution from road traffic. This paper focuses on road traffic accidents - a major cost of transport and an issue for transport planners, policy makers and traffic engineers worldwide. A reduction in road casualties is now an important aim of transport policy and as such it is essential to know what factors are responsible for road accidents before any efficient policy response can be identified.

Much research has been conducted to identify the various factors affecting road casualties (see Shankar et al, 1995; Shefer and Rietveld, 1997; Abdel-Aty and Radwan, 2000; Ivan et al., 2000; Noland and Oh, 2004; Lord et al, 2005; Aguero-Valverde and Jovanis, 2006; and Kim et al. 
2006). These factors are related to road infrastructure, traffic and socio-demographic characteristics, land use and the environment. Two important factors however have not been properly evaluated however in the literature, namely, the spatial impact of area-wide road speed and curvature on traffic accidents while controlling for other factors. It is normally hypothesised that a spatial area with higher average speed may be associated with higher fatalities and serious injuries and an area with lower average speed may be associated with higher slight injury accidents. The quantity of road curvature of a particular area (i.e., the quantity of curved roads) may also have an impact on traffic accidents within the area. These two factors will be investigated in this paper to identify how they contribute to counts of the number of road traffic casualties while controlling for other factors such as road length, socioeconomic variables and traffic flow.

This paper attempts to employ Negative Binomial (NB) models to explore the various factors affecting road casualties in England using spatially disaggregated ward level cross-sectional data. Counts of the number of road traffic accidents within a particular spatial unit can be viewed as a function of various area-wide factors. This basic framework can be expressed as follows:

Counts of accidents $=f$ (traffic characteristics, socio-demographic, road infrastructure, and environment related factors)

It is hypothesised that different area-wide factors affect different road casualties. Therefore, various types of casualty have to be estimated, such as fatalities, serious injuries, slight injuries, casualties related to motorised transport, non-motorised transport and vulnerable road users. The primary objective is to see how area-wide average speed and road curvature affect different types of road casualties while controlling for other factors such as road characteristics and socioeconomic variables.

The paper is structured as follows. First, a summary of the relevant studies are provided; then a brief overview of the data used in the analysis is presented followed by a description of the statistical models used. The next section presents the results from different statistical models 
and the associated discussions. Finally, conclusions are drawn and further research suggestions are presented.

\section{LITERATURE REVIEW}

In previous research road casualties have normally been measured in terms of the roadway, such as intersections or road segments or at different spatial boundaries such as counties, districts, traffic zones, zip codes or other census areas. The general approach has been to develop a relationship between road accidents and the contributing factors using various statistical models. Such a relationship has been developed at either individual road or area-level. A number of recent studies suggest that area-based models are more appropriate than individual road-based models since the former takes into account system-wide effects (Barker et al., 1999; Noland and Oh, 2004; Haynes et al., 2007). As such, in this paper, the focus is on the area-based accident models.

Several researchers have investigated the relationship between speed and road accidents (see Shefer and Rietveld, 1997; Aljanahi et al. 1999; Ossiander and Cummings, 2002; Kockelman and $\mathrm{Ma}, 2007)$. These studies are often based on a disaggregated individual road-level speed. For example, Shefer and Rietveld (1997) proposed a hypothesis that the rate of road fatalities is strongly related to traffic density, speed and congestion, which is supported by empirical evidence such that the fatality rate is lower during the morning period compared to other times of the day. Their findings are not conclusive since it has not been possible to identify which factors (speed, density, or congestion) play a more important role in reducing fatalities during the morning peak period. This is due to the fact that these three factors are inter-related. Other factors, such as poor night time visibility also need to be controlled for. Aljanahi et al. (1999) found that the number of accidents would reduce if the speed limit could be lowered. In some cases, the relationship between mean speed and the accident rate is significant. Generally accidents are more serious at higher speeds. They also suggest that speed variance also plays an important role. Ossiander and Cummings (2002) examined the change of the freeway speed limit in Washington State using time series data and found that an increased speed limit was associated with a higher fatality rate. The spatial differences in road speeds among various 
spatial units however may affect road accidents. This has not been evaluated. A recent study by Kockelman and Ma (2007) examined the freeway speed and speed variation preceding crashes in California while controlling for other factors such as weather and lighting conditions, finding that there was no evidence that speed condition influences crash occurrence. This may be due to the data aggregation and crash-time reporting errors as suggested by the authors. Their study is also based on disaggregate road-level data.

An analysis of road curvature (i.e., the quantity of curved roads in an area) and road casualties has been primarily studied by Milton and Mannering (1998) and Haynes et al (2007). Milton and Mannering (1998) developed such a relationship for the case of sections of highways and suggested that curved sections may not necessarily cause more traffic accidents. Haynes et al (2007) studied road curvature and its association with traffic crashes at the district level (a census area) in England and Wales. Their studies developed a number of measures for road curvature and found that at the district level road curvature is a protective factor meaning that more curved roads in an area results in less road accidents. Similar research based in New Zealand (Haynes et al., 2008), concludes that road curvature has an inverse relationship with fatal crashes on urban settings.

Recent research has investigated the influence of other factors in spatial variations on road accidents (Miaou et al., 2003; Hadayeghi et al., 2003; Graham and Glaister. 2003; Ladron et al., 2004; Noland and Oh, 2004; Noland and Quddus, 2004; Aguero-Valverde and Jovanis, 2006; Kim et al. 2006). These studies have focused on different types of road casualties, exploring various area-level explanatory factors such as land use, population, employment, road length, land-use mix, area deprivation (i.e., poverty), alcohol consumption (i.e., drink driving) and vehicle miles travelled (VMT).

Washington et al. (1999) compared fatal crashes between southeastern and non-southeastern United States and concludes that regional difference exist due to, e.g. differences in seal-belt usage and speed limits. Hadayeghi et al. (2006) conducted an area-wide (traffic zones of the City of Tornoto) accident analysis to examine the temporal transferability of accident prediction models, in which various factors e.g. volume capacity (V/C) ratio, population, and road length 
were considered. In their study, negative binomial models were used to examine effects of these factors at different time period (1996 vs. 2001).

In terms of analysis at the spatially disaggregated ward (a census area) level based on data for England, Graham and Glaister (2003) found that urban scale, density and land-use mix affect pedestrian casualties. They used proxy variables namely proximate population and employment to take account of the impact of traffic flows. Noland and Quddus (2004) also conducted a spatially disaggregated ward level analysis finding that urbanised areas have fewer casualties while areas with higher employment or areas that are more deprived suffer more casualties. Roadway characteristics (such as types of roadway, junctions, and roundabouts) have little effects on traffic casualties, especially fatalities. Amoros et al. (2003) investigated road accidents among several areas in France in order to explore whether observed differences in traffic casualties can be explained by differences in road types and socioeconomic characteristics between countries. Kim et al. (2006) investigated the influence of land use, population, employment and economic activity on accidents based on a grid-based structure. Some recent examples of area-wide based road safety studies include: Delmelle and Thill (2008), who investigated young and adult bicycle crashes in the City of Buffalo, NY, based on "Census Tracts" level using stepwise ordinary least squares (OLS) regression analysis. Similarly a case study in Chicago undertaken by Thakuriah and Cottrill (2008) was also based on "Census Tracts" level. They examined pedestrian accident data using a Poisson regression model. Kar and Datta (2008) studied driver behaviour trying to identify areas with safety issues due to driver behaviour. They calculated Safety Performance Index (SPI) to examine and rank counties in the State of Arizona.

Most of the studies on accident modelling employed a NB regression model to develop the relationship between area-wide traffic accidents and different contributing factors (Graham and Glaister, 2003; Amoros et al., 2003; Noland and Quddus, 2004; Haynes et al., 2007). Recent studies however have developed a relationship between area-wide traffic accidents and various contributing factors using a spatial econometric approach to address the issues of unmeasured spatial correlation among neighbouring spatial units. For instance, Miaou et al. (2003) reviewed methods used in existing studies on disease mapping and pointed out how such methods could 
be employed in accident research. MacNab (2004) demonstrated how Bayesian hierarchical modelling could be applied to area-based accident analysis. Most recently Aguero-Valverde and Jovanis (2006) have compared Full Bayes (FB) hierarchical models with negative binomial models in a spatial analysis of road casualties using county-level cross-sectional time-series data in Pennsylvania, finding that they are generally consistent with each other if analysing fatal crash rates. They suggest however that spatial correlation should be taken into account in order to analyse non-fatal injuries. Their results suggest that both fatal and injury crash rates decrease with the increase in vehicle miles travelled (VMT) and that area deprivation is positively associated with fatal crash rates.

In this paper we do not employ spatial econometric models as above, but will be taking into account such spatial effects by introducing a proxy variable within the NB model.

\section{DATA Description}

The spatial units of this analysis are census wards of England based on the UK Census 2001. There are a total of 8,019 spatial units though we only have data for 7,969 wards. The GIS data of such ward boundaries were obtained from the EDINA UKBORDERS datasets and the STATS19 UK national road accident database was employed to obtain disaggregated accident data. Ward-level total road casualties of different categories were then calculated from this disaggregated accident data using a GIS package, MapInfo. Road casualties on ward boundaries were assigned to wards randomly ${ }^{1}$. In order to avoid a lot of wards with zero accident counts, especially for the case of fatal accidents,, STATS19 data for 2000 to 2002 were aggregated. Road characteristics such as total lengths of motorways, A-roads, B-roads and minor roads were obtained from UK Ordnance Survey (OS). The total number of nodes (mainly junctions) and roundabouts were also obtained from the same source. Socioeconomic data were obtained from the UK census 2001, and ward-level average road speed and traffic volume data were obtained from Graham and Glaister (see Graham and Glaister, 2006) who estimated these variables at the ward level from the traffic demand data (for the year 2000)

\footnotetext{
${ }^{1}$ This is due to positioning errors in both accident location and ward boundary spatial data.
} 
supplied by the UK Department for Transport (DfT). Graham and Glaister (2006) were employed speed-flow relationships (adjusting for road type and area type) and were then applied to flow data for spot locations and the resulting estimates of speed were extrapolated to wards based on their region, area type and road composition. It should be noted that this process involved considerable weighted averaging to produce estimates of average traffic speeds for wards. No external validation of the average road speed data is carried out as reference road speed data are not available to the authors.

Due to the movement of traffic between neighbouring wards, traffic from neighbouring wards is considered when calculating total traffic activities for a particular ward. This results in total traffic activities (TTA) for each ward. TTA is considered a better measure than the actual traffic volume in a ward in this analysis as TTA can take account of traffic activities from other wards so it serves as a better exposure to potential risk. TTA for a particular ward is calculated from the model suggested by Graham and Glaister (2003). This is presented below.

$$
T T A_{i}=T V_{i}+\sum_{j=1}^{N-1} \frac{T V_{j}}{d_{i j}} \quad \text { for } i \neq j, d_{i j} \neq 0
$$

where $T V_{i}$ is the traffic volume of ward $i, T V_{j}$ is the traffic volume of ward $j, d_{i j}$ is the centreto-centre distance between wards $i$ and $j$, and $N$ is the total number of wards. Traffic volume is measured in passenger car units (PCU).

In order to examine the effect of road curvature on road casualties, we employed the following equation developed by Haynes et al (2007) to calculate ward-level road curvature. This is known as bend density $(B D)$ :

$$
B D_{i}=\frac{S P_{i}-n_{i}}{L_{i}}, \quad L_{i} \neq 0
$$

where $S P_{i}$ is the total shape points (i.e., vertices) of all roads within a ward $i, n_{i}$ is the total number of nodes (junctions and end points of roads) of ward $i$, and $L_{i}$ is the total length of all roads of ward $i$. 
Summary statistics for the data used in the analysis are presented in Table 1, which gives a list of variables used in the model. Mean, standard deviation (S.D.), minimum and maximum values of each variable are also presented.

\section{Insert table 1 here}

As can be seen in Table 1, there are 20 independent variables, and 9 of them are dummy variables representing the nine regions of England. Motorways, A roads, B roads and minor roads are four types of roads in England. Motorways and A roads carry relatively high traffic volumes when compared to $B$ roads and minor roads. Considering that the sizes of wards vary so road length could be inappropriate to represent the road network condition in a ward, as such we transform the road length to road length densities to account for this.

Due to data unavailability, environmental factors were not included.

It is noticeable from Table 1 that variables associated with road casualty and road infrastructure have a minimum value of 0 (except bend density) meaning that there were no accidents or no existence of a particular type of road. The "bend density" variable has 7968 observations instead of 7969 observations as other variables, which is because one ward (Clovelly Bay in South West) was reported as having 0 total road length according to our data. To calculate bend density, the total length of road cannot be 0 according to equation (2), so to solve this problem this observation has to be eliminated from our sample.

There is a large variation in the average speed among the wards with the mean traffic speed of $49.2 \mathrm{~km} / \mathrm{h}$ for all wards, a minimum speed of $9.4 \mathrm{~km} / \mathrm{h}$ (a ward from the central London) and the maximum speed is $104.8 \mathrm{~km} / \mathrm{h}$ (a ward from the North West of England). The spatial distribution of area-wide average traffic speed and road curvature is shown in Figures 1 and 2 for part of England including the London area. As can be seen from Figure 1, as expected wards within an urban area (e.g., London in this case) have relatively low average speed compared with wards within a rural area.

Insert figures 1 and 2 here 
Figure 2 suggest some important characteristics in our road density data. One would expect that roads within an urban area are straighter than those of a rural area. However, Figure 2 does not support this hypothesis as bend density of wards within a rural area are less than that of wards within an urban area. The measure of bend density however (see equation 2) largely depends on the amount of total road vertices that subsequently depends on the way a road network was digitised.

Three road user types are categorized to be examined as follows:

- Motorised transport (MT): such as occupants of motorised vehicles of cars, trucks, buses, and trams (no motorcycle).

- Non-Motorised Transport (NMT): Cyclists, horse riders and pedestrians.

- Vulnerable Road Users' (VRUs): Pedestrians, cyclists, motorcyclists and horse riders.

An initial analysis of data was also conducted to see whether there is a specific relationship between road casualties and other contributing factors. For instance, Figure 3 shows a linear association between total traffic casualties and total traffic activity.

\section{Insert figure 3 here}

Such positive relationships illustrated in Figure 3 are expected as total traffic activity is regarded as one of the main exposures to potential risks of accidents. Although the literature indicates that there is a strong relationship between traffic speed and fatal accidents (Ossiander and Cummings, 2002), we do not find a clear linear relationship between accidents and speed as shown in Figure 4. This may be due to the fact that other factors affecting traffic accidents need to be taken into account while developing a relationship between traffic accidents and road speed. 


\section{Statistical Model}

Road traffic accident data are classified as "count data" for which Negative Binomial (NB) regression models are more appropriate (e.g., Shankar et al, 1995; Milton and Mannering, 1998; Abdel-Aty and Radwan, 2000; Lord, 2000; Ivan et al., 2000). The generalised linear relationship between the expected accident counts $\mu_{i}$ and the explanatory variables $\mathbf{X}_{i}$ can be expressed as follows:

$$
\ln \left(\mu_{i}\right)=\beta_{0}+\boldsymbol{\beta} \mathbf{X}_{i}+\varepsilon_{i}
$$

where $\beta$ is the vector of coefficient of explanatory variables to be estimated; and $\varepsilon$ is a random term.

As stated in section 2 NB models are not capable of accounting for the spatial correlation (due to the variations in topography and weather conditions) among wards. Aguero-Valverde and Jovanis (2006) employed a full Bayesian hierarchical model and found the existence of spatial dependence among spatial units for the case of injury accidents. To address the unobserved regional variations (e.g. topography and weather due to data unavailability) within England, we employed an alternative and less complex approach. This was to add a series of dummy variables representing different regions of England (Figure 5) into the NB models. England is divided into 9 statistical regions: London, South East, South West, Eastern, West Midlands, East Midlands, North East, North West and Yorkshire. It should be noted that the 9 standard regions may not be the best approach to divide England into regions with similar topography and weather conditions. This option is the most convenient however, and we assume the wards within each region have similar topography and weather characteristics.

\section{Insert figure 5 here}

\section{Results And Discussion}

Our primary objective has been to develop the relationship between area-wide (ward-level) road casualties and the main contributing factors such as average speed and road curvature while 
controlling for other factors. Due to a large variation among the values of the explanatory variables, some of the variables such as total traffic activities (TTA), population and employment have been transformed into a logarithmic scale. This allows for ease of interpretation of the coefficients of these variables. The coefficients of log-transformed variables are the elasticities of casualties with respect to these variables. To reduce the effect of heteroscedasticity which is normally present in a cross-sectional dataset, robust standard errors have been used to estimate t-statistics for all parameters in all the models. The correlation coefficient of each pair of independent variables is also tested and the result suggests that the independent variables are not correlated to each other as the highest correlation coefficient was found to be 0.63 between Log(Population) and Log(Employment). This suggests that multicollinearity is not a problem in our data.

A series of NB models were estimated for fatalities, serious injuries, and slight injuries associated with total casualties (Table 2), motorised transport (Table 3), non-motorised transport (Table 4) and vulnerable road users (Table 5). The overdispersion parameter is found to be statistically and significantly different from zero (at the $95 \%$ confidence level) in all models suggesting that the NB models are superior to the Poisson models for the data we have used. The likelihood ratio that is a measure of the goodness-of-fit ranges from 0.1 to 0.21 in the NB models estimated in this study. These values are consistent with other likelihood ratios of NB models found in the literature (e.g., Abdel-Aty and Radwan, 2000; Noland and Quddus, 2004). The majority of variables in the fatality models were found to be statistically significant except roundabouts and the log of population (Table 2) although average speed is significant at the $90 \%$ confidence level only. In the serious injury model, nodes and average speed become statistically insignificant variables, and in the slight injury model, all variables are found statistically significant except one spatial variable. As for spatial variations, all dummy variables were found to be statistically significant except for the North West in the slight injury model suggesting that it is essential to control for spatial variation among wards.

\section{Insert tables 2 and 3 here}


Compared to the results presented in Table 2, the number of statistically significant variables is relatively less in the models presented in Table 3 for road casualties associated with motorised transport. This confirms our initial hypothesis that the area-wide factors affecting different types of accidents are different. The statistically insignificant variables in the motorised fatality model are B-road density, nodes, roundabouts, and average speed. In the motorised serious injury model, the only insignificant variable is nodes whereas in the motorised slight injury model, the only insignificant variable is minor road density.

The results for NMT fatalities, serious injuries and slight injuries are presented in Table 4. Motorway density becomes statistically insignificant in all three NMT models. A number of factors including average speed and curvature become statistically insignificant in the NMT fatality model. Roundabouts becomes insignificant in the NMT serious injury model and road curvature is found to be insignificant in the slight injury model.

\section{Insert table 4 here}

The last series of NB models were estimated for casualties related to vulnerable road users (VRUs). This kind of road users are considered more 'vulnerable' compared to motorized transport due to different physical conditions. The results for VRUs fatalities, serious injuries and slight injuries are presented in Table 5. As expected, the set of significant variables across all models are different from the set of significant variables presented in Tables 2, 3, and 4.

\section{Insert table 5 here}

As revealed from Tables 2, 3, 4, and 5 different ward-level factors affect road casualties differently. This is an expected result and in the following paragraphs, we interpret the impact of various explanatory variables on ward-level road casualties. 


\subsection{Average Traffic Speed}

Our expectation is that average speed should have an impact on road casualties while we controlling for other factors.

Average speed is found to be statistically significant and positively associated with total fatalities. This confirms our study hypothesis. The mean elasticities ${ }^{2}$ of total fatalities with respect to average speed are found to be 0.095 meaning that a $1 \%$ increase in average speed of a ward would increase fatalities by $0.095 \%$ all other factors remaining the same. Average speed is found to be statistically significant and negatively associated with total slight injuries. The mean elasticity of slight injuries with respect to traffic speed is -0.074 suggesting that a $1 \%$ increase in average speed would decrease slight injuries by $0.07 \%$. This result indicates that speed has a different effect on different types of road casualties.

Disaggregated by accident types, for the case of MT, average speed is found to be significant in the serious injury model (with a positive coefficient) and slight injury model (with a negative coefficient). This is reasonable as serious injuries are often associated with motorized transport. Surprisingly, this variable is found to be insignificant in the MT fatality model. This is because there are fewer MT related ward-level fatal accidents as the average fatalities for all wards is only 0.6. Most of the variations in MT fatalities are explained by other factors such as road infrastructure, socioeconomic, and traffic activities factors. For the case of NMT and VRUs, average speed is found to be statistically significant with a negative coefficient in both the serious injury and slight injury models. This means that wards with lower average speed have more slight and serious injuries. This is an expected result. This is because one would expect that low traffic speed indicates a high level of traffic congestion that results in more injury accidents. Average speed is found to be insignificant in the NMT fatality and VRUs fatality models.

Therefore, it can be said that the ward-level average speed does have an effect on traffic casualties while controlling for other contributing factors such as traffic activities, road 
characteristics, and socioeconomic variables. Generally speed has an inverse relationship with slight injuries, which is reasonable as higher speed often means less congestion, i.e. less traffic volume; and hence it would be more likely to result in more serious, especially motorised injuries as indicated in our results.

Compared to previous studies, our results support that higher speed is associated with more serious road casualties (e.g. Aljanahi et al. 1999; Ossiander and Cummings 2002). We also have revealed it is more often the motorized transport related serious road casualties. Previous studies however mainly investigated the speed limit, which is not completely equivalent to average speed as in our study. Aljanahi et al. (1999) and Ossiander and Cummings (2002) suggested that it is necessary to investigate speed variance to see how it relates to road casualties. Due to data unavailability, we did not look at speed variance. Therefore further studies needs to be done on this issue to fully understand the relationship between speed and road casualties.

\subsection{Road Curvature}

Road curvature in our study is calculated by total shape points (i.e., intermediate points of a road segment determining the degree of curvature of the segment) of a ward from all road segments divided by the total length of all roads within the ward. This is termed the bend density of a ward. A ward with a high value of bend density suggests that the ward has relatively more curved roads. Haynes et al. (2007) used this variable and found that at a district-level (a census area that is much bigger than a ward) bend density negatively affects road traffic casualties. Our aim was also to re-investigate this using ward data while controlling for other factors such as traffic volume, traffic speed, road types, and other socioeconomic factors.

In all models considered in this study except NMT \& VRU fatality models, road curvature is found to be statistically significant with a negative coefficient. This finding is in-line with the finding by Haynes et al. (2007) and also confirms our hypothesis. This may be because drivers

\footnotetext{
${ }^{2}$ Mean elasticity is defined as $E=\frac{\partial \mu}{\partial x} \cdot \frac{\bar{x}}{\mu}=\beta \mu \cdot \frac{\bar{x}}{\mu}=\beta \bar{x}$.
} 
would be more aware of the road conditions present in a curved road. An evidence of this is that drivers usually drive more carefully through residential and commercial areas, where the roads are often more curved as indicated in Figure 2. Another possible reason is that, increased bend density could be caused by fewer side roads, which would reduce the risk of potential conflicts and consequently crashes. Notice that the value of the coefficient for this variable is consistently and relatively high compared with the values of other covariates included in the models. This is because the value of road curvature is relatively low with a mean value of 0.025 .

Therefore, it can be said that more curved roads within a ward can be considered as a protective factor regarding road safety for the case of our data. However recent study (Haynes et al., 2008) using similar methods applied in New Zealand does not completely confirm our results here: road curvature (including bend density and the other 3 measures) is significantly negatively related to fatal crashes on urban roads. This is not always true in rural areas. It is clear that data sources from a different country will result in different conclusions due to different road networks, demographic and topographical conditions. Furthermore, as the author suggested, there are four road curvature measures and they are not necessarily consistent with each other, suggesting that one measure may not be sufficient to reveal the road curvature nature. Clearly, more research should be done on this area.

\subsection{Other Contributing Factors}

Road density (i.e., the total length of road within a ward per square $\mathrm{km}$ area of the ward) of different roads (motorway, A road, B road, minor road) was taken as an explanatory variable in all models to see whether it had any influence on road casualties. Other road infrastructure variables were the total number of nodes and roundabouts within a ward. It is reasonable to assume that a ward with higher road density has more opportunity for accidents to happen as road users are exposed to potential dangers along the road. Our results support this hypothesis.

$A$ and $B$ road densities are always found to be statistically significant at the $95 \%$ confidence level in all models considered in this study, with the exception in the motorised fatality model where B road density is not statistically significant (see Tables 2, 3, 4, and 5). These variables 
are positively related with road casualties suggesting that wards with larger A and B road densities have more road casualties of any category and vice versa.

Motorway density is statistically significant in all models related to total traffic casualties (Table 2) and motorised casualties (Table 3). Similar to A road and B road densities, the relationship between motorway density and these casualties is positive. This is because motorways are mainly used by MT and wards with a high density motorway normally have high severity casualties. This variable is found to be statistically insignificant in all models related to NMT and VRUs casualties. This is an expected result as pedestrians, cyclists, and horse riders do not use motorways.

Minor road density reveals a mixed result. This variable is found to be statistically significant with a positive coefficient in the total serious injury, total slight injury, NMT serious injury, NMT slight injury, VRUs serious injury and VRUs slight injury models. It is statistically significant with a negative coefficient in the total fatality, MT fatality, and MT serious injury models. This variable is statistically insignificant in the NMT fatality and VRUs fatality models. Generally, minor road density has a negative relationship with fatalities suggesting that fewer fatalities occur on minor roads compared to other types of roads. Drivers on minor roads are more aware of circumstances as these roads are often located at residential or shopping areas with a $30 \mathrm{mph}$ speed limit. However, serious injuries and slight injuries associated with NMT and VRUs are more common in minor roads compared with other types of roads.

Roundabouts are known to cause fewer traffic accidents compared with traditional junctions (Hels and Orozova-Bekkevold, 2007). To investigate this, the total number of roundabouts within a ward was included in all models. In most of the models, this variable was found to be statistically insignificant. This may be due to the fact that we do not have data on whether a roundabout is signalised or un-signalised. Previous research suggests that signalised roundabouts are safer than unsignalised roundabouts (De Brabander and Vereeck, 2007). Our results suggest that wards with a high number of roundabouts have higher casualties associated with MT (see Table 3) and lower slight injuries associated with both NMT (Table 4) and VRUs (Table 5). 
In our study, nodes consist of both junctions and end points (cul-de-sac) of roads. Junctions are normally known as accident hotspots and on the other hand, accidents may not happen at the end point of a road (i.e., cul-de-sac). Since we do not have data for junctions, nodes within a ward are included in all models as a proxy measure for junctions. Our results suggest that this variable is statistically significant with a positive coefficient in most models. This means that wards with a high number of junctions have more casualties. This variable however is found to be insignificant in the total serious injury, MT fatality and serious injury, NMT fatality models. Our results would be more conclusive if we had data available on whether a particular junction is signalised or unsignalised.

Total traffic activity (in PCU) is an indicator of traffic activity within each ward in our model. We calculated an equivalent traffic volume for a particular ward by taking into account traffic volume from surrounding wards. This is known as total traffic activity (TTA) of a ward and as with road density. TTA is regarded as exposure to potential risks for road users. Therefore, our expectation is that wards with high TTA would have high traffic casualties. Our results suggest that TTA is statistically significant at $95 \%$ confidence level and positively associated with road casualties in most models (see Table 2, 3, 4, and 5). The only exception is in the NMT slight injury model where it is found to be statistically insignificant. This confirms that increased TTA would generally produce more casualties. Surprisingly, we found a strong negative association between TTA and NMT slight injuries (95\% confidence level). This is an unexpected result.

Socioeconomic factors such as population and employment are included in all models considered in our study to see whether they affect road casualties. Our expectation is that both variables should have positive associations with casualties because these factors reflect the level of activity within a ward. The results are consistent with our expectation.

Population and employment are found to be statistically significant with a positive coefficient in all models, with the exception in the total fatalities model where population is not significant (see Tables 2, 3, 4, and 5). This result is consistent with the findings of Noland and Quddus (2004). We also found that the relationship between population/employment and MT slight injuries is particularly strong compared to MT fatalities and serious injuries. One shortcoming of this 
analysis is that it does not consider other important socioeconomic factors, such as age cohorts, gender, alcohol consumption, and seat-belt usage. This is due to the unavailability of the data.

Spatial variations were examined by using a series of dummy variables representing the 9 regions in England. In the models, dummy variable for Yorkshire was taken as a reference case. The purpose of these dummy variables is to take into account unobserved variations in topography, weather conditions and land use types. The results confirm the existence of a regional effect in our data. For example, the differential coefficient for London is found to be 0.19 in the VRUs slight injury model suggesting that there are about 0.19 more slight injuries in the London region compared with the Yorkshire region.

\section{CONCLUSIONS}

This paper has investigated the factors affecting area-level (an England census ward - Ward) traffic casualties using a non-spatial negative binomial (NB) regression model. Ward-level traffic casualty data has been disaggregated by the severity of the casualty such as fatalities, serious injuries, slight injuries and by severity of the casualty related to various road users such as motorised transport (MT), non-motorised transport (NMT), and vulnerable road users (VRUs). A series of NB models have been developed for each category of casualty and the effects of spatial variation among wards controlled to some extent by introducing a series of dummy variables related to the nine regions of England. We have been particularly interested to see whether ward-level traffic speed and road curvature had any effect on various types of casualties. Our results suggest that increased average speed within a ward is positively associated with total fatalities and MT serious injuries of the ward. For all other categories of casualty, average speed was either insignificant or significant but negatively associated with serious and slight injury casualties of NMT and VRUs. Since wards with a low average speed are normally located in urban areas where traffic congestion is a common issue, the negative association between speed and slight injury casualties could be justified. However, the negative association between speed and serious injuries could not be rationalised. Road curvature was statistically significant in most models (except NMT fatality and VRU fatality models) and 
negatively associated with casualties. This suggests that wards with more curved roads have fewer casualties. The results associated with the controlling factors such as road infrastructure (e.g., road length, junctions, roundabouts) and socioeconomic variables (e.g., population and employment) were also found to be coherent in all models.

Due to the unavailability of data we were not able to examine other important factors such as weather conditions (e.g. annual rainfall), signalised and unsignalised junctions and roundabouts, and socioeconomic factors (e.g. age cohorts, alcohol consumption, and seat-belt usage). Further research is required in order to address these issues to provide more proper results. It would also be interesting to see how the results would change when a spatial model (similar to the model employed by MacNab, 2004; and Aguero-Valverde and Jovanis, 2006) is applied to the data.

\section{REFERENCES}

Abdel-Aty, M.A. and Radwan, A.E., 2000, Modeling traffic accident occurrence and involvement, Accident Analysis \& Prevention, 32(5), 633-642.

Aguero-Valverde, J. and Jovanis, P.P., 2006, Spatial analysis of fatal and injury crashes in Pennsylvania, Accident Analysis \& Prevention, 38(3), 618-625.

Aljanahi, A.A.M., Rhodes, A.H. and Metcalfe, A.V., 1999. Speed, speed limits and road traffic accidents under free flow conditions. Accident Analysis \& Prevention, 31(1-2), 161-168.

Amoros, E., Martin, J.L. and Laumon, B., 2003, Comparison of road crashes incidence and severity between some French counties, Accident Analysis \& Prevention, 35(4), 537-547.

Barker, J., Farmer, S. and Taylor, M., 1999, The development of accident-remedial intervention levels for rural roads, Transport Research Laboratory, Crowthorne, Berkshire.

De Brabander, B. and Vereeck, L., 2007, Safety effects of roundabouts in Flanders: signal type, speed limits and vulnerable road users, Accident Analysis \& Prevention, 39(3), 591-599.

Delmelle, E. and Thill, J. 2008, Urban Bicyclists - A Spatial Analysis of Adult and Youth Traffic Hazard Intensity, Proceedings of the Paper Presented at the 87nd Annual Meeting of the Transportation Research Board. Washington, D.C., January 13-17, 2008.

Graham, D.J. and Glaister, S., 2003, Spatial variation in road pedestrian casualties: the role of urban scale, density and land-use mix, Urban Studies, 40(8), 1591-1607.

Graham, D.J. and Glaister, S., 2006, Spatial implication of transport pricing, Journal of Transport Economics and Policy, 40(2), 173-201. 
Haynes, R., Jones, A., Kennedy, V., Harvey, I. and Jewell, T., 2007, District variations in road curvature in England and Wales and their association with road-traffic crashes, Environment and Planning A, 39(5), 1222-1237.

Haynes, R., Lake, I.R., Kingham, S., Sabel, C.E., Pearce, J. and Barnett, R. 2008, The influence of road curvature on fatal crashes in New Zealand, Accident Analysis \& Prevention, vol. 40, no. 3, pp. 843-850.

Hadayeghi, A., Shalaby, A.S., and Persaud, B.N., 2003, Microlevel accident prediction models for evaluating safety of urban transportation systems, Transportation Research Record 1840, 87-95.

Hadayeghi, A., Shalaby, A.S., Persaud, B.N. and Cheung, C. 2006, Temporal transferability and updating of zonal level accident prediction models, Accident Analysis \& Prevention, vol. 38, no. 3, pp. 579-589.

Hels, T. and Orozova-Bekkevold, I., 2007, The effect of roundabout design features on cyclist accident rate, Accident Analysis \& Prevention, 39 (2), 300-307.

Ivan, J.N., Wang, C. and Bernardo, N.R. 2000, Explaining two-lane highway crash rates using land use and hourly exposure, Accident Analysis \& Prevention, 32(6), 787-795.

Kar, K. and Datta, T.K. 2008, An Approach to Identify Areas with Traffic Safety Issues Due to Driver Behavioral Factors - Arizona Experience, Proceedings of the Paper Presented at the 87nd Annual Meeting of the Transportation Research Board. Washington, D.C., January 13-17, 2008.

Kim, K., Brunner, I. and Yamashita, E., 2006. Influence of land use, population, employment, and economic activity on accident's. Transportation Research Record 1953, 56-64.

Kockelman, K.M. and Ma, J. 2007, Freeway speeds and speed variations preceding crashes, within and across lanes, Journal of the Transportation Research Forum, vol. 46, no. 1.

Ladron de Guevara, F., Washington, S. and Oh, J. 2004, Forecasting Crashes at the Planning Level: Simultaneous Negative Binomial Crash Model Applied in Tucson, Arizona, Transportation Research Record, vol. 1897, no. -1, pp. 191-199.

Lord, D., 2000, The prediction of accidents on digital networks: characteristics and issues related to the application of accident prediction models. Ph.D. Thesis, Department of Civil Engineering, University of Toronto, Toronto.

Lord, D., Manar, A., Vizioli, A., 2005, Modeling crash-flow-density and crash-flow-V/C ratio relationships for rural and urban freeway segments, Accident Analysis \& Prevention, 37(1), 185199.

MacNab, Y.C. 2004, Bayesian spatial and ecological models for small-area accident and injury analysis, Accident Analysis \& Prevention, 36(6), 1019-1028.

Miaou, S., Song, J.J. and Mallick, B. 2003, Roadway traffic crash mapping: a space-time modeling approach, Journal of Transportation and Statistics, vol. 6, no. 1, pp. 33-57.

Milton, J. and Mannering, F. 1998, The relationship among highway geometrics, traffic-related elements and motor-vehicle accident frequencies, Transportation, 25(4), 395-413.

Noland, R.B. and Oh, L., 2004, The effect of infrastructure and demographic change on trafficrelated fatalities and crashes: a case study of Illinois county-level data, Accident Analysis \& Prevention, 36(4), 525-532.

Noland, R.B. and Quddus, M.A. 2004, A spatially disaggregate analysis of road casualties in England, Accident Analysis \& Prevention, 36(6), 973-984. 
Ossiander, E.M. and Cummings, P., 2002, Freeway speed limits and traffic fatalities in Washington State, Accident Analysis \& Prevention, 34(1), 13-18.

Shankar, V., Mannering, F. and Barfield, W., 1995, Effect of roadway geometrics and environmental factors on rural freeway accident frequencies, Accident Analysis \& Prevention, 27(3), 371-389.

Shefer, D. and Rietveld, P., 1997, Congestion and safety on highways: towards an analytical model", Urban Studies, 34(4), 679-692.

Thakuriah, P. and Cottrill, C., 2008, Evaluating Pedestrian Risk in Environmental Justice Areas, Proceedings of the Paper Presented at the 87nd Annual Meeting of the Transportation Research Board. Washington, D.C., January 13-17, 2008.

Washington, S., Metarko, J., Fomunung, I., Ross, R., Julian, F. and Moran, E. 1999/1, An interregional comparison: fatal crashes in the southeastern and non-southeastern United States: preliminary findings, Accident Analysis \& Prevention, vol. 31, no. 1-2, pp. 135-146. 
Table 1 Summary statistics of variables used in the models

\begin{tabular}{|c|c|c|c|c|c|}
\hline Variables & $\mathrm{N}$ & Mean & S.D. & Minimum & Maximum \\
\hline \multicolumn{6}{|l|}{ Dependent variables } \\
\hline Total fatalities & 7969 & 1.10039 & 1.56244 & 0 & 15 \\
\hline Total serious injuries & 7969 & 12.04919 & 11.84616 & 0 & 236 \\
\hline Total slight injuries & 7969 & 91.17054 & 97.83176 & 0 & 1746 \\
\hline Total motorized casualties & 7969 & 74.43305 & 78.51608 & 0 & 1400 \\
\hline Total non motorized casualties & 7969 & 19.89196 & 29.66699 & 0 & 856 \\
\hline Total vulnerable road users' casualties & 7969 & 29.82758 & 40.81776 & 0 & 1276 \\
\hline Motorized fatalities & 7969 & 0.59091 & 1.16025 & 0 & 14 \\
\hline Motorized serious injuries & 7969 & 6.21308 & 6.92554 & 0 & 119 \\
\hline Motorized slight injuries & 7969 & 67.62906 & 73.48241 & 0 & 1321 \\
\hline Non motorized fatalities & 7969 & 0.31208 & 0.66587 & 0 & 10 \\
\hline Non motorized serious injuries & 7969 & 3.53018 & 5.32685 & 0 & 136 \\
\hline Non motorized slight injuries & 7969 & 16.04969 & 24.52243 & 0 & 721 \\
\hline VRU fatalities & 7969 & 0.50847 & 0.86033 & 0 & 10 \\
\hline VRU serious injuries & 7969 & 5.82432 & 7.11361 & 0 & 186 \\
\hline VRU slight injuries & 7969 & 23.49479 & 34.06918 & 0 & 1080 \\
\hline \multicolumn{6}{|l|}{ Road Infrastructure } \\
\hline Motorway length $(\mathrm{m})$ per $\mathrm{km} 2$ of area & 7969 & 37.27122 & 145.95970 & 0 & 1893.925 \\
\hline A road length $(\mathrm{m})$ per $\mathrm{km} 2$ of area & 7969 & 592.55800 & 667.03400 & 0 & 10028.53 \\
\hline$B$ road length $(m)$ per $k m 2$ of area & 7969 & 278.88830 & 403.96990 & 0 & 3962.742 \\
\hline Minor road length $(\mathrm{m})$ per $\mathrm{km} 2$ of area & 7969 & 4327.10200 & 3387.20200 & 0 & 24033.95 \\
\hline Number of roundabouts & 7969 & 1.38324 & 2.26095 & 0 & 78 \\
\hline Number of nodes & 7969 & 90.92195 & 58.13864 & 0 & 933 \\
\hline Bend density (Curvature $\mathrm{m}^{-1}$ ) & 7968 & 0.02520 & 0.00694 & 0.00140 & 0.05356 \\
\hline \multicolumn{6}{|l|}{ Traffic Characteristics } \\
\hline Total traffic activity (pcu) & 7969 & 8063495 & 6127939 & 397288.3 & $6.49 \mathrm{E}+07$ \\
\hline Average speed $(\mathrm{km} / \mathrm{h})$ & 7969 & 49.24543 & 21.19803 & 9.413134 & 104.7612 \\
\hline \multicolumn{6}{|l|}{ Demographic Characteristics } \\
\hline Resident population & 7969 & 6166.248 & 4118.081 & 106 & 35102 \\
\hline Employment & 7969 & 2783.106 & 5682.174 & 8 & 173127 \\
\hline \multicolumn{6}{|l|}{ Spatial Variations } \\
\hline London & 7969 & 0.07943 & 0.27043 & 0 & 1 \\
\hline South East & 7969 & 0.18810 & 0.39082 & 0 & 1 \\
\hline South West & 7969 & 0.13678 & 0.34364 & 0 & 1 \\
\hline Eastern & 7969 & 0.14029 & 0.34731 & 0 & 1 \\
\hline West Midlands & 7969 & 0.09550 & 0.29392 & 0 & 1 \\
\hline East Midlands & 7969 & 0.11055 & 0.31360 & 0 & 1 \\
\hline North East & 7969 & 0.06086 & 0.23909 & 0 & 1 \\
\hline North West & 7969 & 0.12624 & 0.33214 & 0 & 1 \\
\hline Yorkshire & 7969 & 0.06224 & 0.24161 & 0 & 1 \\
\hline
\end{tabular}




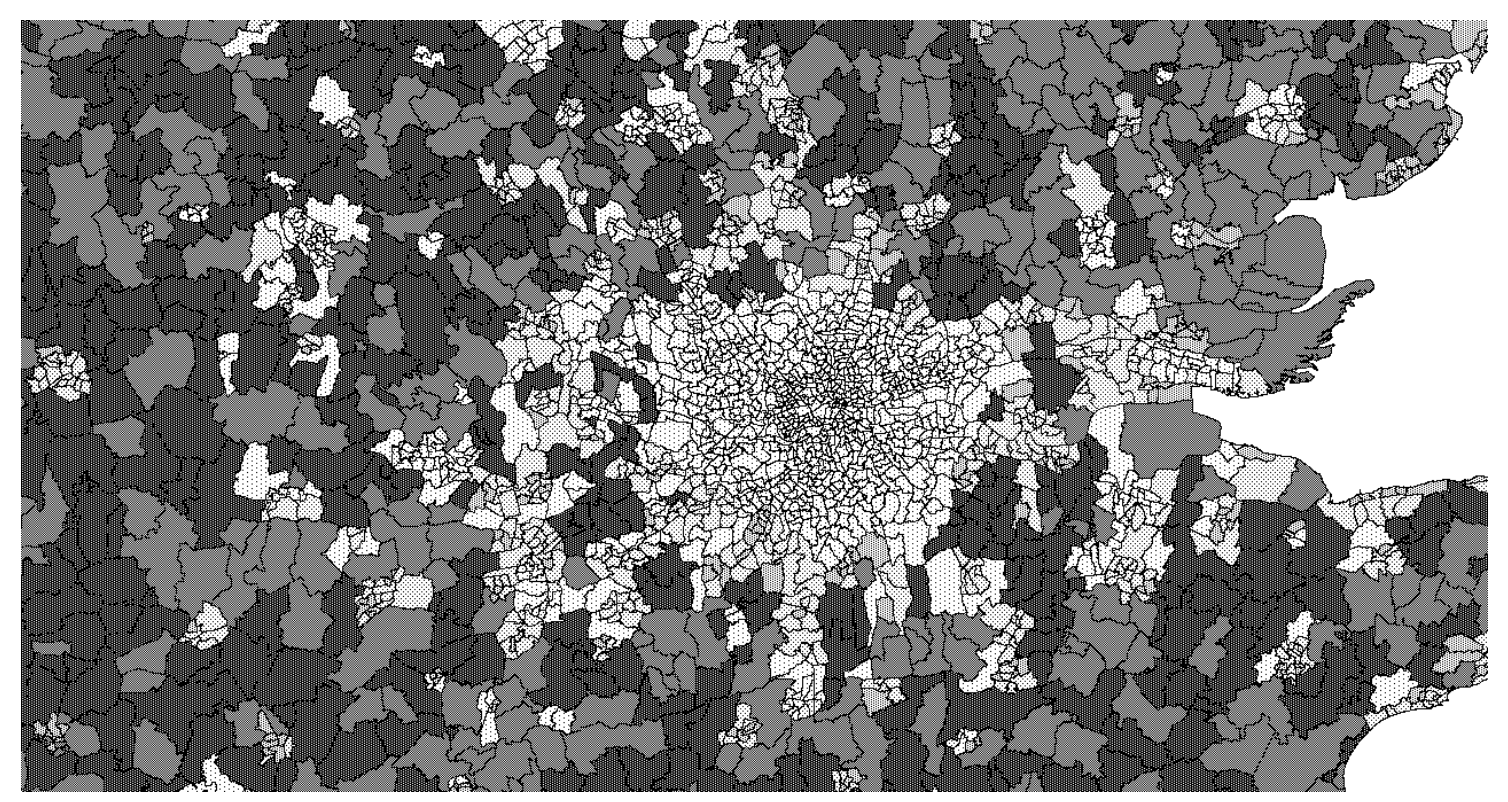

Ward-level average speed distribution
瀜 75.4 to 104.8 (1711)
39.7 to 75.4 (1534)
38.5 to $39.7(1306)$
33.5 to 38.5 (1811)
. 9.4 to $33.5(1607)$

Figure 1 Spatial distribution of ward-level average road speed 


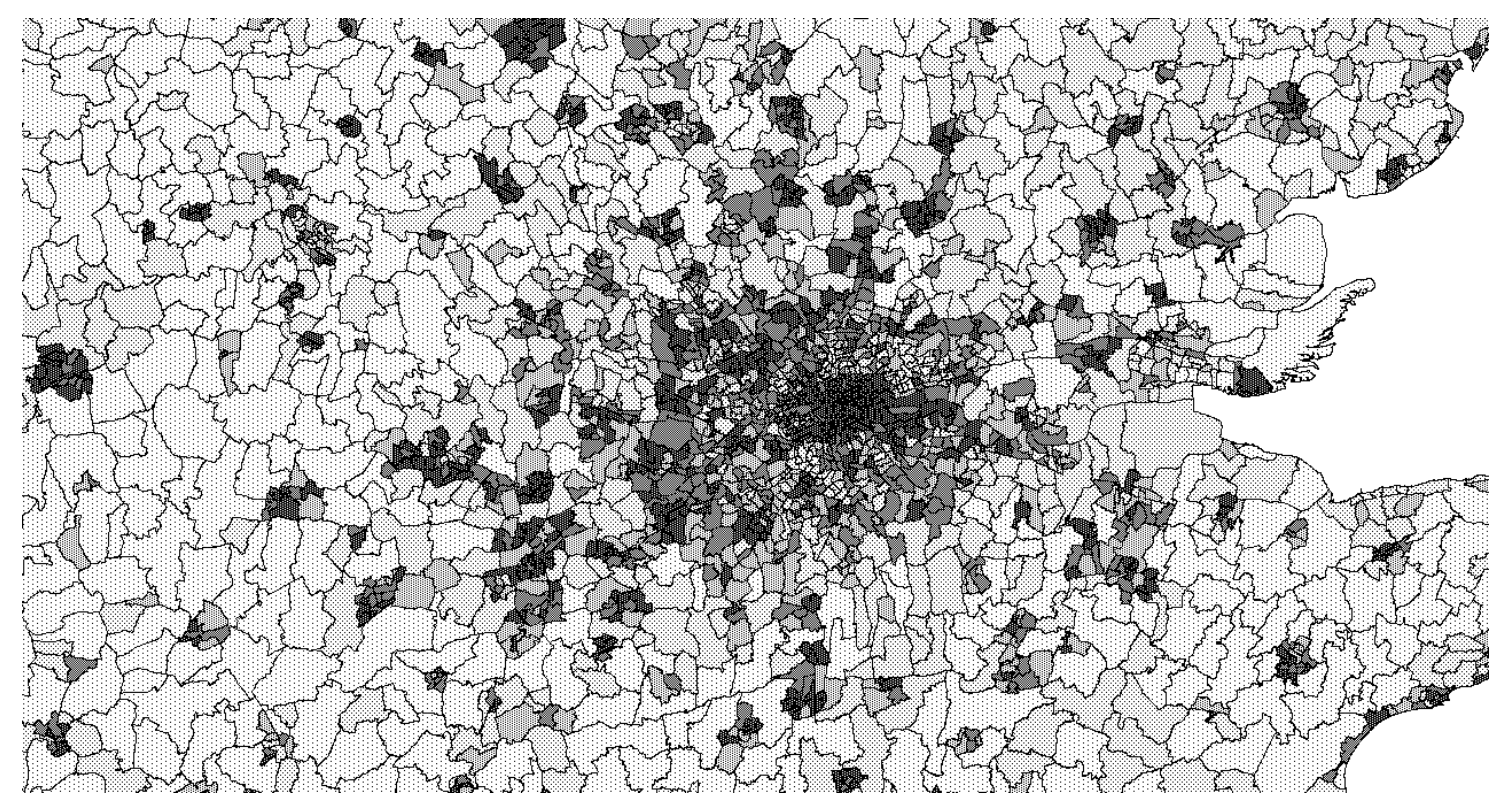
䦕 0.0308 to 0.0536 (1629)
0.0274 to $0.0308(1516)$
0.0236 to 0.0274 (1643)
0.0185 to 0.0236 (1547)
0 to 0.0185 (1634)

Ward-level bend density distribution

Figure 2 Spatial distribution of ward-level bend density 


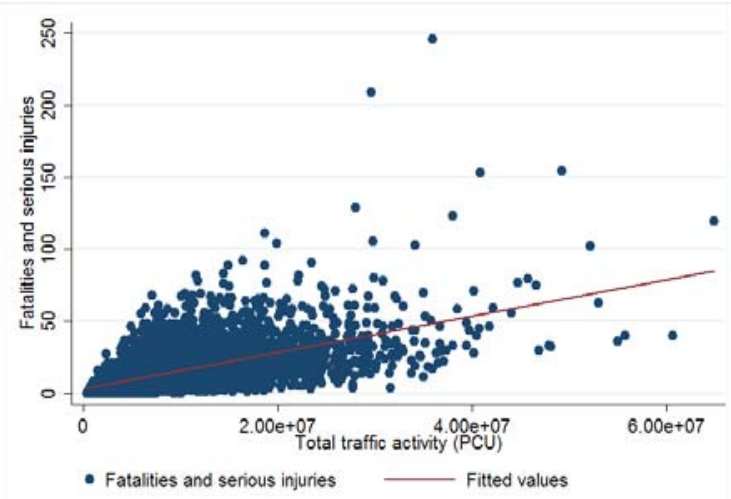

(a) Fatalities and serious injuries

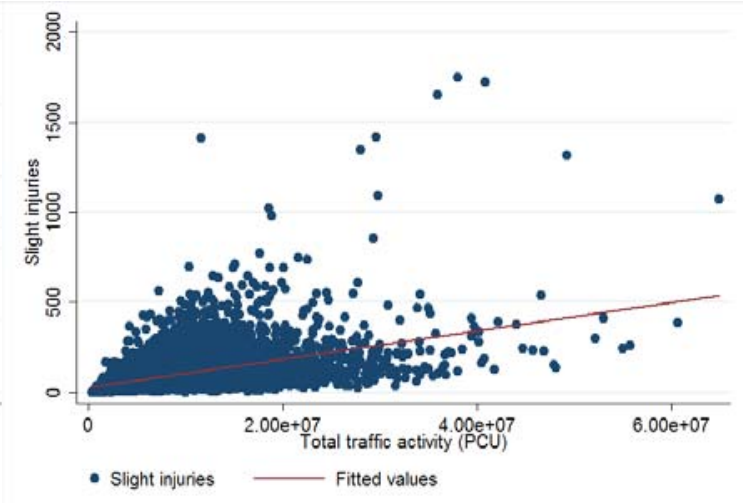

3(b) Slight injuries

Figure 3 Relationships between traffic casualties and total traffic activity 


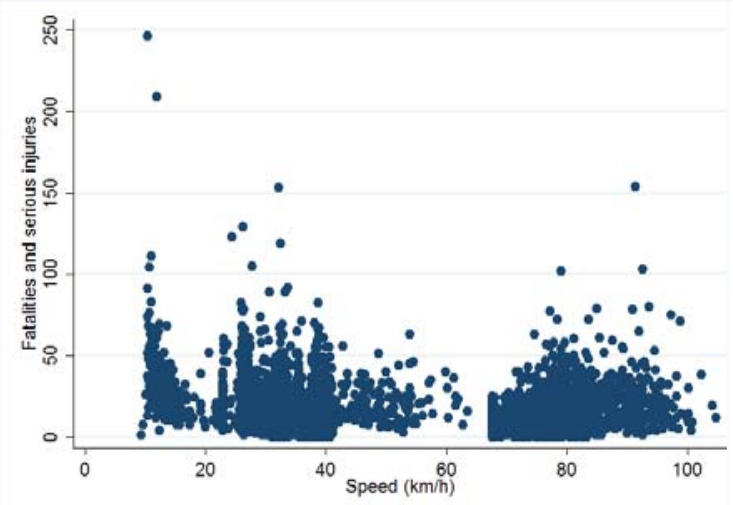

(a) Fatalities and serious injuries

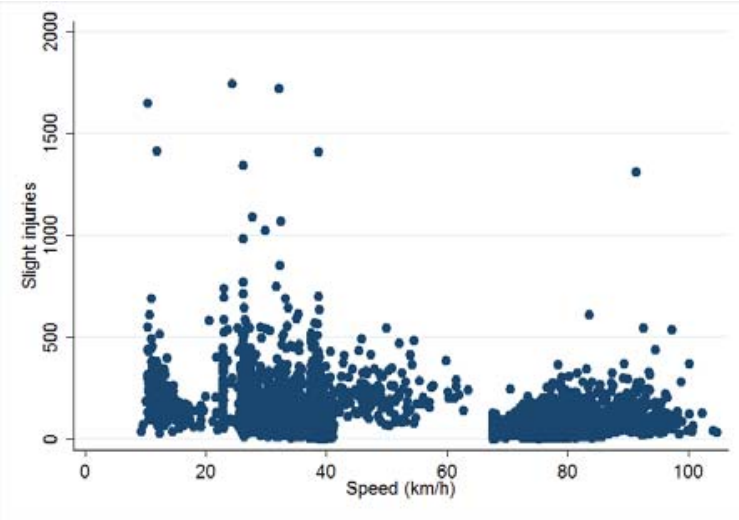

(b) Slight injuries

Figure 4 Traffic causalities and averaged speed 


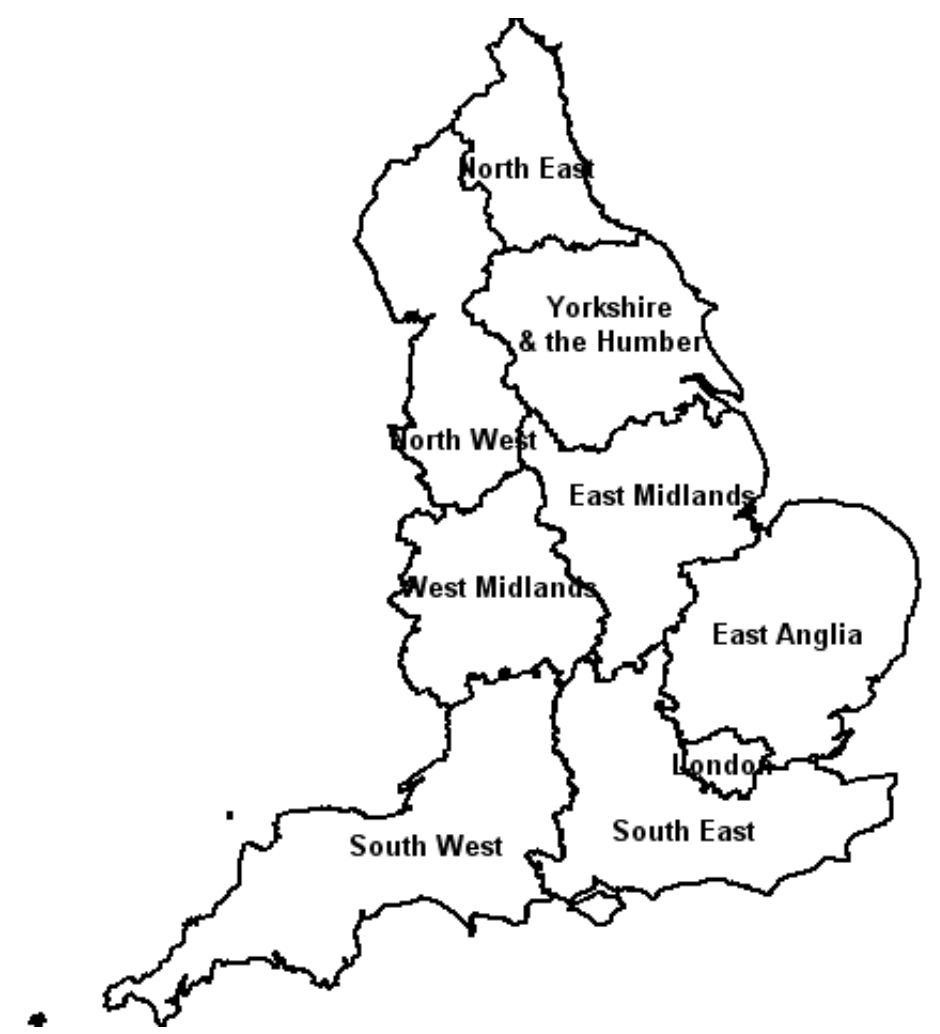

Figure 5 Nine statistical regions of England 
Table 2 Estimation results of NB models for total road casualties

\begin{tabular}{|c|c|c|c|c|c|c|}
\hline \multirow[b]{2}{*}{ Explanatory Variables } & \multicolumn{2}{|c|}{ Fatalities } & \multicolumn{2}{|c|}{ Serious Injuries } & \multicolumn{2}{|c|}{ Slight Injuries } \\
\hline & Coeff & t-Stat & Coeff & t-Stat & Coeff & t-Stat \\
\hline \multicolumn{7}{|l|}{ Roadway Infrastructure } \\
\hline Motorway length $(\mathrm{m})$ per $\mathrm{km} 2$ of area & 0.00027 & 3.22 & 0.00025 & 4.85 & 0.00054 & 10.81 \\
\hline A road length $(m)$ per km2 of area & 0.00014 & 4.87 & 0.00009 & 6.48 & 0.00013 & 11.93 \\
\hline$B$ road length $(m)$ per km2 of area & 0.00017 & 4.34 & 0.00016 & 9.41 & 0.00013 & 9.83 \\
\hline Minor road length $(\mathrm{m})$ per $\mathrm{km} 2$ of area & -0.00006 & -7.51 & 0.00001 & 1.86 & 0.00001 & 5.75 \\
\hline Number of roundabouts & 0.00260 & 0.5 & 0.01885 & 5.23 & 0.02138 & 6.17 \\
\hline Number of nodes & 0.00066 & 2.02 & -0.00003 & -0.21 & 0.00036 & 2.35 \\
\hline Bend density (Curvature $\mathrm{m}^{-1}$ ) & -21.83962 & -6.24 & -17.12301 & -10.51 & -12.47388 & -9.22 \\
\hline \multicolumn{7}{|l|}{ Traffic Characteristics } \\
\hline Log(Total traffic activity in pcu) & 0.74514 & 20.65 & 0.60460 & 34.64 & 0.53487 & 35.59 \\
\hline Average speed (km/h) & 0.00193 & 1.76 & 0.00076 & 1.43 & -0.00149 & -3.15 \\
\hline \multicolumn{7}{|l|}{ Demographic Characteristics } \\
\hline Log(Resident population) & 0.03912 & 0.98 & 0.13865 & 7.67 & 0.29618 & 15.74 \\
\hline Log(Employment) & 0.13358 & 6.65 & 0.18809 & 20.5 & 0.24202 & 30.47 \\
\hline \multicolumn{7}{|l|}{ Spatial Variations } \\
\hline London & -0.14447 & -1.82 & 0.08398 & 2.24 & -0.08532 & -2.67 \\
\hline South East & -0.27445 & -4.4 & -0.28936 & -9.95 & -0.11182 & -4.55 \\
\hline South West & -0.43228 & -6.52 & -0.60399 & -19.57 & -0.23054 & -9.15 \\
\hline Eastern & -0.28505 & -4.36 & -0.25424 & -8.11 & -0.12203 & -4.48 \\
\hline West Midlands & -0.20828 & -3.14 & -0.36404 & -11.31 & -0.14051 & -5.24 \\
\hline East Midlands & -0.10451 & -1.6 & -0.21969 & -6.92 & -0.08943 & -3.34 \\
\hline North East & -0.36870 & -4.29 & -0.53948 & -14.66 & -0.07199 & -2.34 \\
\hline North West & -0.23874 & -3.98 & -0.26903 & -9.39 & 0.03419 & 1.42 \\
\hline Yorkshire (Reference case) & - & & - & & - & \\
\hline Constant & -12.41604 & -21.67 & -9.22968 & -33.09 & -8.19959 & -33.09 \\
\hline Overdispersion parameter & 0.31641 & 14.60 & 0.18302 & 37.17 & 0.17572 & 51.31 \\
\hline \multicolumn{7}{|l|}{ Descriptive Statistics } \\
\hline Number of observations & \multicolumn{2}{|c|}{7968} & \multicolumn{2}{|c|}{7968} & \multicolumn{2}{|c|}{7968} \\
\hline Log-pseudolikelihoodlikelihood (at conver & \multicolumn{2}{|c|}{-10237.276} & \multicolumn{2}{|c|}{-23908.344} & \multicolumn{2}{|c|}{-37926.133} \\
\hline Log-likelihood ratio index & \multicolumn{2}{|c|}{0.11610} & \multicolumn{2}{|c|}{0.14199} & \multicolumn{2}{|c|}{0.13244} \\
\hline
\end{tabular}


Table 3 Estimation results of NB models for Motorised Transport (MT) casualties

\begin{tabular}{|c|c|c|c|c|c|c|}
\hline \multirow[b]{2}{*}{ Explanatory Variables } & \multicolumn{2}{|c|}{ Fatalities } & \multicolumn{2}{|c|}{ Serious Injuries } & \multicolumn{2}{|c|}{ Slight Injuries } \\
\hline & Coeff & t-Stat & Coeff & t-Stat & Coeff & t-Stat \\
\hline \multicolumn{7}{|l|}{ Roadway Infrastructure } \\
\hline Motorway length $(\mathrm{m})$ per $\mathrm{km} 2$ of area & 0.00057 & 5.03 & 0.00049 & 6.7 & 0.00068 & 12 \\
\hline A road length $(\mathrm{m})$ per $\mathrm{km} 2$ of area & 0.00010 & 1.92 & 0.00004 & 2.17 & 0.00011 & 8.48 \\
\hline B road length $(\mathrm{m})$ per $\mathrm{km} 2$ of area & 0.00011 & 1.53 & 0.00014 & 5.68 & 0.00012 & 8.01 \\
\hline Minor road length $(\mathrm{m})$ per $\mathrm{km} 2$ of area & -0.00013 & -9.66 & -0.00004 & -9.43 & -0.000002 & -0.63 \\
\hline Number of roundabouts & 0.00584 & 0.69 & 0.03114 & 6.43 & 0.03016 & 7.17 \\
\hline Number of nodes & 0.00007 & 0.15 & -0.00010 & -0.44 & 0.00045 & 2.57 \\
\hline Bend density (Curvature $\mathrm{m}^{-1}$ ) & -34.93094 & -6.42 & -24.38828 & -10.48 & -15.27546 & -10.28 \\
\hline \multicolumn{7}{|l|}{ Traffic Characteristics } \\
\hline Log(Total traffic activity in pcu) & 0.79652 & 15.86 & 0.73498 & 31.2 & 0.62114 & 37.17 \\
\hline Average speed $(\mathrm{km} / \mathrm{h})$ & 0.00124 & 0.84 & 0.00175 & 2.48 & -0.00115 & -2.17 \\
\hline \multicolumn{7}{|l|}{ Demographic Characteristics } \\
\hline Log(Resident population) & 0.11716 & 2.08 & 0.08703 & 3.71 & 0.28395 & 16.12 \\
\hline Log(Employment) & 0.06791 & 2.19 & 0.11318 & 8.99 & 0.20169 & 23.99 \\
\hline \multicolumn{7}{|l|}{ Spatial Variations } \\
\hline London & -0.39698 & -3.08 & 0.30201 & 5.77 & -0.21253 & -5.71 \\
\hline South East & -0.34755 & -4.03 & -0.26849 & -6.5 & -0.13664 & -4.75 \\
\hline South West & -0.39749 & -4.39 & -0.65228 & -15.12 & -0.28743 & -9.82 \\
\hline Eastern & -0.30072 & -3.38 & -0.24792 & -5.67 & -0.12724 & -4.03 \\
\hline West Midlands & -0.12406 & -1.37 & -0.32878 & -7.47 & -0.13458 & -4.37 \\
\hline East Midlands & -0.10336 & -1.15 & -0.19906 & -4.56 & -0.08922 & -2.83 \\
\hline North East & -0.38030 & -3.02 & -0.59325 & -11.03 & -0.02413 & -0.69 \\
\hline North West & -0.25998 & -2.98 & -0.30681 & -7.38 & 0.08844 & 3.1 \\
\hline Yorkshire (Reference case) & - & & - & & - & - \\
\hline Constant & -13.38587 & -16.77 & -10.66150 & -28.24 & -9.32095 & -33.76 \\
\hline Overdispersion parameter & 0.65108 & 13.81 & 0.31321 & 33.72 & 0.22035 & 51.94 \\
\hline \multicolumn{7}{|l|}{ Descriptive Statistics } \\
\hline Number of observations & \multicolumn{2}{|c|}{7968} & \multicolumn{2}{|c|}{7968} & \multicolumn{2}{|c|}{7968} \\
\hline Log-pseudolikelihoodlikelihood (at convergence) & \multicolumn{2}{|c|}{-7189.9682} & \multicolumn{2}{|c|}{-20156.679} & \multicolumn{2}{|c|}{-36392.923} \\
\hline Log-likelihood ratio index & \multicolumn{2}{|c|}{0.12694} & \multicolumn{2}{|c|}{0.12849} & \multicolumn{2}{|c|}{0.12126} \\
\hline
\end{tabular}


Table 4 Estimation results of NB models for Non-Motorised Transport (NMT) casualties

\begin{tabular}{|c|c|c|c|c|c|c|}
\hline \multirow[b]{2}{*}{ Explanatory Variables } & \multicolumn{2}{|c|}{ Fatalities } & \multicolumn{2}{|c|}{ Serious Injuries } & \multicolumn{2}{|c|}{ Slight Injuries } \\
\hline & Coeff & t-Stat & Coeff & t-Stat & Coeff & t-Stat \\
\hline \multicolumn{7}{|l|}{ Roadway Infrastructure } \\
\hline Motorway length $(\mathrm{m})$ per $\mathrm{km} 2$ of area & -0.00003 & -0.25 & 0.00001 & 0.16 & 0.00005 & 1.14 \\
\hline A road length $(\mathrm{m})$ per $\mathrm{km} 2$ of area & 0.00017 & 4.66 & 0.00017 & 9.9 & 0.00020 & 14.46 \\
\hline B road length $(\mathrm{m})$ per $\mathrm{km} 2$ of area & 0.00013 & 2.47 & 0.00010 & 4.93 & 0.00007 & 4.25 \\
\hline Minor road length $(\mathrm{m})$ per $\mathrm{km} 2$ of area & 0.00001 & 1.24 & 0.00005 & 11.78 & 0.00005 & 13.48 \\
\hline Number of roundabouts & -0.00764 & -1.01 & -0.00009 & -0.03 & -0.00677 & -2.42 \\
\hline Number of nodes & 0.00065 & 1.47 & 0.00073 & 3.4 & 0.00144 & 6.5 \\
\hline Bend density (Curvature $\mathrm{m}^{-1}$ ) & -2.36989 & -0.44 & -6.43234 & -2.92 & -2.78802 & -1.33 \\
\hline \multicolumn{7}{|l|}{ Traffic Characteristics } \\
\hline Log(Total traffic activity in pcu) & 0.47362 & 7.3 & 0.08544 & 3.15 & -0.08758 & -3.96 \\
\hline Average speed $(\mathrm{km} / \mathrm{h})$ & 0.00013 & 0.06 & -0.00508 & -6.1 & -0.00617 & -9.58 \\
\hline \multicolumn{7}{|l|}{ Demographic Characteristics } \\
\hline Log(Resident population) & 0.28388 & 3.85 & 0.51485 & 12.94 & 0.62303 & 12.52 \\
\hline Log(Employment) & 0.27163 & 8.9 & 0.33778 & 26 & 0.39024 & 30.77 \\
\hline \multicolumn{7}{|l|}{ Spatial Variations } \\
\hline London & -0.16418 & -1.39 & -0.09189 & -1.94 & 0.00298 & 0.08 \\
\hline South East & -0.20721 & -2.09 & -0.24071 & -5.91 & -0.04249 & -1.25 \\
\hline South West & -0.37371 & -3.52 & -0.44538 & -9.93 & -0.01091 & -0.3 \\
\hline Eastern & -0.24301 & -2.24 & -0.16102 & -3.75 & -0.06202 & -1.73 \\
\hline West Midlands & -0.21759 & -2.07 & -0.19152 & -4.57 & -0.04645 & -1.34 \\
\hline East Midlands & -0.16489 & -1.49 & -0.14293 & -3.15 & -0.05190 & -1.48 \\
\hline North East & -0.18153 & -1.46 & -0.25488 & -5.19 & -0.06717 & -1.61 \\
\hline North West & -0.10494 & -1.15 & -0.06560 & -1.77 & 0.00572 & 0.18 \\
\hline Yorkshire (Reference case) & - & & - & & - & - \\
\hline Constant & -13.24564 & -13.71 & -7.16825 & -18.28 & -4.58751 & -14.78 \\
\hline Overdispersion parameter & 0.24681 & 4.82 & 0.16264 & 20.48 & 0.16912 & 27.83 \\
\hline \multicolumn{7}{|l|}{ Descriptive Statistics } \\
\hline Number of observations & \multicolumn{2}{|c|}{7968} & \multicolumn{2}{|c|}{7968} & \multicolumn{2}{|c|}{7968} \\
\hline Log-pseudolikelihoodlikelihood (at convergence) & \multicolumn{2}{|c|}{-5118.9574} & \multicolumn{2}{|c|}{-15172.721} & \multicolumn{2}{|c|}{-23889.855} \\
\hline Log-likelihood ratio index & \multicolumn{2}{|c|}{0.10713} & \multicolumn{2}{|c|}{0.20184} & \multicolumn{2}{|c|}{0.21041} \\
\hline
\end{tabular}


Table 5 Estimation results of NB models for Vulnerable Road Users' (VRUs) casualties

\begin{tabular}{|c|c|c|c|c|c|c|}
\hline \multirow[b]{2}{*}{ Explanatory Variables } & \multicolumn{2}{|c|}{ Fatalities } & \multicolumn{2}{|c|}{ Serious Injuries } & \multicolumn{2}{|c|}{ Slight Injuries } \\
\hline & Coeff & t-Stat & Coeff & t-Stat & Coeff & t-Stat \\
\hline \multicolumn{7}{|l|}{ Roadway Infrastructure } \\
\hline Motorway length $(\mathrm{m})$ per $\mathrm{km} 2$ of area & 0.00001 & 0.07 & 0.00001 & 0.29 & 0.00007 & 1.93 \\
\hline A road length $(\mathrm{m})$ per $\mathrm{km} 2$ of area & 0.00014 & 4.34 & 0.00014 & 9.17 & 0.00019 & 15.08 \\
\hline B road length $(\mathrm{m})$ per $\mathrm{km} 2$ of area & 0.00017 & 4.02 & 0.00015 & 8.18 & 0.00010 & 7.02 \\
\hline Minor road length $(\mathrm{m})$ per $\mathrm{km} 2$ of area & -0.00001 & -1.28 & 0.00003 & 10.38 & 0.00004 & 13.87 \\
\hline Number of roundabouts & 0.00218 & 0.35 & 0.00629 & 2 & 0.00094 & 0.36 \\
\hline Number of nodes & 0.00075 & 1.99 & 0.00016 & 0.91 & 0.00078 & 4.35 \\
\hline Bend density (Curvature $\mathrm{m}^{-1}$ ) & -6.83588 & -1.56 & -7.88022 & -4.53 & -3.99239 & -2.34 \\
\hline \multicolumn{7}{|l|}{ Traffic Characteristics } \\
\hline Log(Total traffic activity in pcu) & 0.63230 & 13.27 & 0.37757 & 18.26 & 0.12627 & 7.13 \\
\hline Average speed $(\mathrm{km} / \mathrm{h})$ & 0.00119 & 0.83 & -0.00154 & -2.53 & -0.00438 & -8.57 \\
\hline \multicolumn{7}{|l|}{ Demographic Characteristics } \\
\hline Log(Resident population) & 0.10025 & 1.89 & 0.28326 & 12.11 & 0.49352 & 14.49 \\
\hline Log(Employment) & 0.18884 & 7.54 & 0.26519 & 25.31 & 0.34756 & 33.33 \\
\hline \multicolumn{7}{|l|}{ Spatial Variations } \\
\hline London & -0.02836 & -0.3 & -0.05725 & -1.38 & 0.19482 & 5.4 \\
\hline South East & -0.18247 & -2.33 & -0.26722 & -7.98 & -0.00060 & -0.02 \\
\hline South West & -0.43250 & -5.17 & -0.51634 & -14.44 & -0.01619 & -0.53 \\
\hline Eastern & -0.27690 & -3.31 & -0.22597 & -6.38 & -0.06107 & -1.97 \\
\hline West Midlands & -0.29862 & -3.52 & -0.34750 & -9.57 & -0.11425 & -3.71 \\
\hline East Midlands & -0.10722 & -1.28 & -0.21580 & -5.76 & -0.04666 & -1.53 \\
\hline North East & -0.33913 & -3.3 & -0.47682 & -11.21 & -0.21076 & -5.73 \\
\hline North West & -0.17135 & -2.28 & -0.20030 & -6.29 & -0.05070 & -1.86 \\
\hline Yorkshire (Reference case) & - & - & - & - & - & - \\
\hline Constant & -12.86117 & -17.2 & -8.53186 & -26.92 & -6.03680 & -22.67 \\
\hline Overdispersion parameter & 0.21843 & 6.63 & 0.16185 & 25.98 & 0.15070 & 34.33 \\
\hline \multicolumn{7}{|l|}{ Descriptive Statistics } \\
\hline Number of observations & \multicolumn{2}{|c|}{7968} & \multicolumn{2}{|c|}{7968} & \multicolumn{2}{|c|}{7968} \\
\hline Log-pseudolikelihoodlikelihood (at convergence) & \multicolumn{2}{|c|}{-6933.2545} & \multicolumn{2}{|c|}{-18855.44} & \multicolumn{2}{|c|}{-26701.985} \\
\hline Log-likelihood ratio index & \multicolumn{2}{|c|}{0.09705} & \multicolumn{2}{|c|}{0.16550} & \multicolumn{2}{|c|}{0.19788} \\
\hline
\end{tabular}

